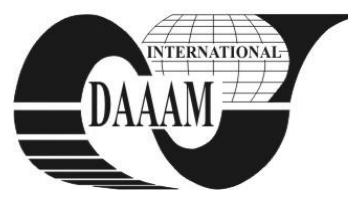

Annals of DAAAM for 2011 \& Proceedings of the 22nd International DAAAM Symposium, Volume 22, No. 1, ISSN 1726-9679 ISBN 978-3-901509-83-4, Editor B. Katalinic, Published by DAAAM International, Vienna, Austria, EU, 2011 Make Harmony between Technology and Nature, and Your Mind will Fly Free as a Bird Annals \& Proceedings of DAAAM International 2011

\title{
EFFECTIVE MACHINE TOOL COSTS REDUCTION METHOD
}

\author{
DOSEDLA, M[ichal] \& BRADAC, F[rantisek]
}

\begin{abstract}
The main building stone of company marketing policy is a product. The product can be some machine, service, information etc. (Tomek \& Vavrova, 2001). From a machine tool point of view the product is not only the machine but also accessory, user manual, servis and training. Nowadays not only producers of macine tool have one important task to reduce production costs. The reason of this step is to bring on the market competitive price of their products. The aim of this paper is to choose several phases of machine tool life-cycle that has main influence on final product costs. The second part deals with two costs reduction methods that were checked in real situations. It is possible to reach up to $30 \%$ costs reduction by using one of them.
\end{abstract}

Key words: costs, machine tool, designing, life-cycle

\section{INTRODUCTION}

The machine tool belongs to main point of machining process any artificial metal part. The machine tool is used in case that geometric dimension of part and quality of surfaces is not possible to achieve by casting, forging, welding etc.

Not only machine tool but also any other product should meets follow features:

- Fulfill customer requirements

- There is a demand after it

- Fulfill directive regulation (safety, ecologic, etc.)

Every manufacturing company tries to manage resources frugally. It can be define by words - minimize costs and maximize profit. Market mechanism is based on coordination of economic subject activity and free selling price (Marek, 2007).

Profit of company that produces and sells machine tools depends on final machine costs and selling price. Difference between company income and costs is company profit.

$$
\mathrm{Pc}=\mathrm{Ic}-\mathrm{Cc}
$$

Company costs $\left(\mathrm{C}_{\mathrm{c}}\right)$ means consumption of input factors during some period whereas company income $\left(I_{p}\right)$ means money value that company got from all activities during the same period (Konecny 2007).

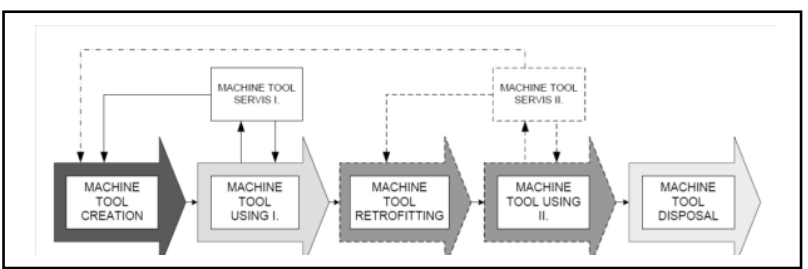

Fig. 1 Diagram of machine tool life-cycle

Increase of company profit can be reached by two approaches in this case. Either increasing of selling price of machine or decreasing of machine costs.

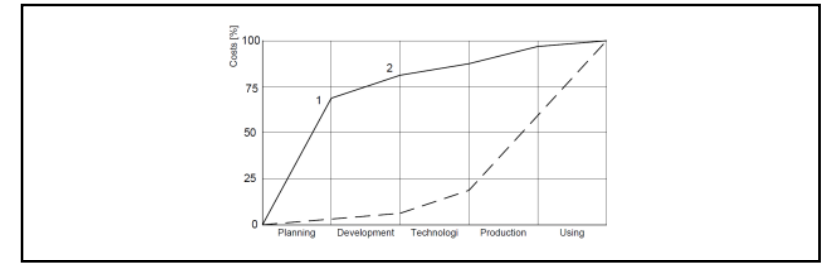

Fig. 1 Costs and reasons of costs origination in particular manufacturing (Janicek, 2007)

It is not possible to increase the machine selling price because of wide competition in machine tool branch in many cases. Thus producers have to try to reduce costs of machine tool creation that is initial stage of machine tool life-cycle (see Fig 1).

Machine tool producer usually knows $3 / 4$ of machine costs at the end of the development phase (initial phase of machine tool creation). Costs draw in this stage are very low (see Fig. 2). This stage has main influence on future machine features and there is possible easily change machine design during development stage.

Whereas costs of machine tool production and assembly are much higher than costs of development stage. Value of this high costs are mostly defined during the development phase. If producer wants to reduce machine tool production costs is necessary to focused mainly at initial machine tool planning and development stage.

Next reason for design cost reduction is the culture of engineering which trains designers almost entirely in the technical side of design, while only giving minimal attention to its other implications (Michaels \& Wood, 1989). This culture makes product performance a higher priority than cost. When that is combined with deadline pressure, cost concerns may be given only minimal attention (Geiger \& Dilts, 1996).

One approach of machine tool costs reduction can be automated design-to-cost.

The purpose of the application is to provide rapid and dynamic feedback during the design process regarding estimated final product cost of a new part design. The system first calculates the cost of a new part design directly from existing computer-aided design, accounting, and other computer-integrated manufacturing databases. It then finds and displays, along with their costs, all existing parts that are similar or 'near' to the proposed part (Geiger \& Dilts, 1996).

\section{EFECTIVE MACHINE TOOL COSTS REDUCTION METHOD}

There are two approaches how to reduce final machine tool costs: after machine production or during machine production.

- Costs reduction of an exist machine tool

- Costs reduction of a future machine tool 


\subsection{Costs reduction method of an exist machine tool}

This reduction method is applied after finishing of first machine tool after calculation of real (final) machine tool costs (before production of next piece) see Fig. 3 .

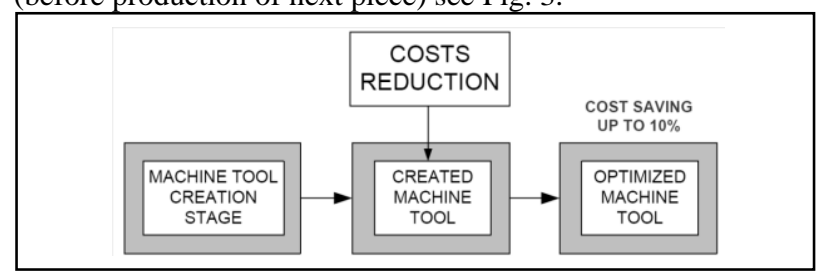

Fig. 3. Diagram of costs reduction method of exist machine tool

This method seams be easy and effective because at the beginning of costs reduction producer knows real machine costs. Unfortunately costs reduction by this method is maximum $10 \%$ (Toshulin) because of follow aspects.

- It is very complicate to change any part of machine without influence at other machine parts.

- Unwillingness of designers to change anything at former designed machine.

- It is complicated to replace some machine purchased components by different one (cheaper).

\subsection{Costs reduction of a future machine tool}

Machine Tool Costs Reduction Method (MTCRM) is used before developing of a new machine or inovation of concurrent machine in this case (see Fig 4). New machine development can comes from market or customer requirements. MTCRM has to be applied within all stages that has influenc on machine tool final costs. Main influenc on machine costs have all phases of machine tool creation stage (see Fig. 4). The higest influence have planning and development stages.

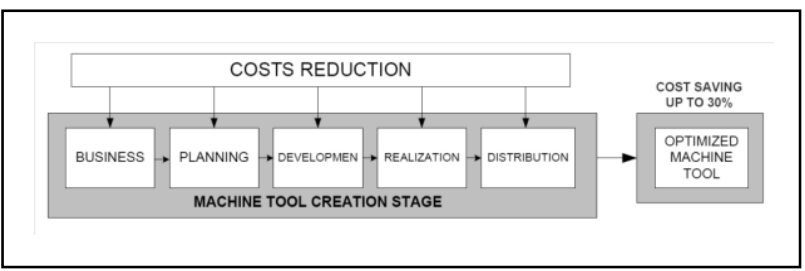

Fig. 4 Diagram of Machine tool costs reduction method (MTCRM) of future machine tool

The first step of this method is determination of the main task = maximal machine costs, that should be keep during the machine tool development and production. Main machine tool features should be known in advance. Maximal machine costs should follow real producer experience or competitors machine price.

There is possible to reach costs reduction up to $30 \%$, if producer uses MTCRM rigorously (Toshulin).

High efficiency of this method is caused early using of this process, within the planning and development sage. Designer doesn't have to keep former solution thus he is able to find a new cheaper solution with the same technical features and the same or better machine quality.

\subsection{Process of Machine Tool Costs Reduction Method}

The first step is definition of all main machine tool functions $\left(\mathrm{F}_{\mathrm{n}}\right)$. Function is a machine feature or performance parameter. Machine tool performance and parameters should be similar to competitors machines $\left(\mathrm{F}_{\mathrm{c}}\right)$.

$$
\mathrm{F}_{\mathrm{n}} \sim \mathrm{F}_{\mathrm{c}}
$$

Example of several vertical lathes features:

- $\quad \mathrm{F} 1 \uparrow$ max. spindle torque (higher than competition)

- F3 $\uparrow$ maximum load (higher)

- $\quad$ F4 =rotary clamping desk diameter (equal)
On the basis of producer experience, machine tool features and competition prices is defined concurrent producer cost $\left(\mathrm{C}_{\mathrm{c}}\right)$ of future developed machine (costs before reduction).

Concurrent costs is reduced by value S [\%] that will means asked reduction of new machine costs.

$$
\mathrm{C}_{\mathrm{r}}=\mathrm{C}_{\mathrm{c}} * \frac{100-\mathrm{S}}{100}
$$

It is not recommended to reduce machine costs in one step. In this case is better to divide machine to several smaller groups and reduce costs of each group separately.

$$
\begin{gathered}
C_{\mathrm{rg} 1}=\mathrm{C}_{\mathrm{cg} 1} * \frac{100-\mathrm{S}}{100} \\
\mathrm{C}_{\mathrm{rg} 2}=\mathrm{C}_{\mathrm{cg} 2} * \frac{100-\mathrm{S}}{100} \\
\downarrow \\
\mathrm{C}_{\mathrm{rgn}}=\mathrm{C}_{\mathrm{rgn}} * \frac{100-\mathrm{S}}{100}
\end{gathered}
$$

Final machine tool costs after reduction is equal summation of all machine groups costs $\left(\mathrm{C}_{\mathrm{rgc}}\right)$. This value should be similar to requested machine costs that producer asked at the beginning of costs reduction process.

$$
\mathrm{C}_{\mathrm{rgc}}=\mathrm{C}_{\mathrm{rg} 1}+\mathrm{C}_{\mathrm{rg} 2}+\cdots+\mathrm{C}_{\mathrm{rgn}} \sim \mathrm{C}_{\mathrm{r}}
$$

\section{CONCLUSION}

Both mentioned reduction methods follows from real application during the machine tool creation at Toshulin Company (producer of vertical CNC lathes). Machine Tool Costs Reduction Method that was used during vhole planning and developing phase saved $30 \%$ of final machine costs. This method is effective approach to reduce machine tools costs.

Final machine tool costs could be reduced more by using of MTCRM during all stages of machine tool creation phase.

Is important to proceed step by step during cost reduction to reach the lowest possible machine costs. Producer should focus mainly at planning and development sage because these phases have main influence on machine tool costs.

Designers shouldn't feel cost reduction like a managing of their work. Costs should be defined like one feature of machine together with machine features.

Nevertheless always main task for producer should be developed and produced the machine that will fulfill all customer requirements and also the machine reliability has to be same or higher than reliability of competitive machines.

\section{REFERENCES}

Geiger, T. S., Dilts, D. M. (1996). Automated design-to-cost: integrating costing into the design decision, ComputerAidedDesign, Vol. 28, Elsevier Science, Great Britain, 1996

Janicek. P. (2007). Systemove pojeti vybranych oboru pro techniky hledani souvislosti, Vysoke uceni technicke v Brne - Nakladatelstvi VUTIUM, Brno 2007, ISBN: 978-807204-55-6

Konecny, M. (2007). Podnikova ekonomika, Akademicke nakladatel. CERM, Brno 2007, ISBN:978-80-214-3465-3

Marek, J. (2007). Integrovany vyvoj vyrobku. Teze inauguracni prednasky, VSB-TU Ostrava, Fakulta strojni, 2007. ISBN 978-80-248-1572-5. s. 40

Michaels, J. V., Wood, W. P. (1989). Design To Cost, Wiley and Sons, New York (1989)

Tomek, G., Vavrova, V. (2001). Vyrobek a jeho uspe ch na trhu, 1. Vydani, Grada publishing, Praha 2001, ISBN: 80-247-0053-0 